\title{
Cell Phone Usage and Social Interaction with Proximate Others: Ringing in a Theoretical Model
}

\author{
Omotayo Banjo, Yifeng Hu and S. Shyam Sundar* \\ Media Effects Research Laboratory, College of Communications, The Pennsylvania State University, University Park, \\ PA 16802, USA
}

\begin{abstract}
Observational research on the social impact of cell phone usage in public places suggests that the mere presence of cell phones in public conflicts the private and public spheres and inhibits social interaction with proximate others (strangers or known persons). The purpose of this paper is to develop a theoretical model for which social effects of cell phone usage in public places documented in observational studies can be empirically tested. In this paper, we discuss various variables to consider in the study of cell phone usage (CPU) and social interaction with proximate others (SIPO). We offer a modest experiment of CPU in the context of social participation, a form of social interaction. Focusing on helping behavior in particular, results indicate that while on the cell phone, users are less likely to offer help. Findings imply that $\mathrm{CPU}$ in public places can distract users from social responsibilities, as they neglect the environment surrounding them.
\end{abstract}

\section{INTRODUCTION}

CNN Headline News host, A.J Hammer commented during his "Extreme Cell Phone" segment, that he had observed a fellow New Yorker watching television via his cell phone on the train seat next to him. To this, he remarks, "There's hardly reason to talk to each other anymore!" The host's comment resonates with the growing concern of the integration of communication technologies in public places. And rightly so, as the interaction between cell phone users in public spaces has become intriguing to both laymen and academics alike.

Much is made of cell phone use in public places, with the older generation being generally scornful of youngsters flipping out their phones in restaurants, classrooms, public transportation and other such venues. Academic scholarship on cell phones has suggested that cell phone use in public places can potentially have negative effects on interaction with proximate others. Mostly studied from an observational approach, such suppositions seem to lack empirical evidence however, thereby identifying a need for a theoretical framework for investigating social and psychological issues pertaining to cell phone use in public. In this paper, the authors make a modest first attempt at developing a theoretical model for better understanding cell phones' impact on society by examining relevant mediating and moderating effects on interpersonal interactions.

First, to demonstrate the problem, we will briefly discuss the effect of cell phones on our interaction with others. Then, we will propose a theoretical model of cell phone usage (CPU) and social interaction with proximate others (SIPO), along with various mediators. Lastly, we will give an exam

*Address Correspondence to this author at the College of Communications, The Pennsylvania State University, 212 Carnegie Bldg., University Park, PA 16802, USA; Tel: 814865 2173; Fax: 814 863-8161;

E-mail: sss12@psu.edu ple of a small case study. Finally, we will discuss other ways in which this model may be applied.

\section{CELL PHONE USAGE AND SOCIAL INTERACTION WITH PROCIMATE OTHERS}

Cell phone usage can be defined as any application of the cell phone as a tool, including talking, text messaging, game playing or the sheer accessibility of the instrument. Originally the cell phone served as a tool for business management. Now, cell phones serve as a tool for social connection, in other words, managing social relationships. Across qualitative and quantitative studies, users of the cell phone all report using their phone for social purposes. However, scholars have argued the cell phone might actually serve as a tool for social isolation (Bugeja, 2005). On the other hand, the cell phone has been argued to function as a social connection device, especially among teens (Ling, 1999a). Therefore, the social use of cell phones has proven to be a rich area for communication research, with researchers exploring various ways in which cell phone use affects social interaction, both isolating and connecting involved persons.

Overall, a plethora of research findings suggest that cell phone usage in social spaces generates negative attitudes as it constitutes a disturbance to proximate others (Bergvik, 2004; Cooper, 2002; Cuminskey, 2005; Plant, 2001; Wei \& Leung, 1999). The accessibility of a cell phone automatically speaks of status and yields generalized attributions towards the user (Rosen, 2005; Ling \& Helmersen, 2000; Katz \& Aspden, 1998). In response to the question of whether or not cell phones bothered others, more than half of the respondents which included cell phone users and non-cell phone users agreed (Ling, 2002). Moreover, as Cumiskey (2005) suggests, public use of new technologies transform our roles from social participant to observer or user of new technologies. In other words, it's not just the user who is engaged in cell phone activity, but the observer becomes involved as a bystander. 
The cell phone has infiltrated such public spaces as restaurants, theaters, public transportation, parks, streets and most other open spaces (Ling, 1999b). However, findings indicate that cell phone use is generally more tolerated in some arenas of public space than others. For instance, cell phone use is prohibited in indoor spaces, such as buses, theaters or restaurants, sometimes by law or by normative expectations (Ling, 1999b). On the other hand, cell phone use in outdoor arenas, like parks, is more tolerable. Furthermore, it has become apparent that cell phone use in public places is defined by proximate others. For one case study, Ling (1999b) found that co-present others openly scorned cell phone users when they judged CPU as inappropriate. Based on the social response, cell phone users became more reluctant to use their phones in particular areas. Therefore we can assume proximate others are significant identifiers of socially acceptable behavior in public spaces, leading us to examine the relationship between cell phone use (CPU) and social interaction with proximate others (SIPO).

Social interaction signifies that we are aware of the existence of others, as well as implies active engagement between two or more parties. It is mostly demonstrated in some form of communication, both verbal and non-verbal. Researchers have measured social interaction by gaze direction, social cues, body communication, and verbal engagement (Burgoon \& Hoobler, 2002; Ling, 1999b, 2002; Scheflen \& Aschcraft, 1976). Although it varies between spaces and contexts, social interaction with proximate others implies that we are not only aware of the presence of proximate others, but regardless of intent, we are communicating with those around us. For instance, while on the phone, cell phone users engage in what is called interproximate and interkinesic communication. That is, the user is functioning in two different locations at the same time, with the person on the phone and with proximate others (Ling, 2002). The latter may be negatively impressed with this kind of interaction, thus altering their environment as well (Rosen, 2005).

Although observational research shows that most cell phone users retreat from social settings when they are using the cell phone in a public place (Ling, 1999b), findings also suggest that cell phone users use the cell phone in public spaces as a form of exclusion (Bugeja, 2005; Ling, 2002). According to observational studies, cell phone users have been seen to acknowledge the presence of strangers, by glancing or gazing, but, by their body language, appear closed to the idea of pursuing any interaction (Ling, 1999b). Regardless, Ling (2002) argues we have a social responsibility to manage our interactions with proximate others, be they strangers or known persons. Based on these arguments, we contend that the sheer accessibility of the cell phone can hinder potentially beneficial social interactions with strangers.

\section{CPU AND SIPO MODEL}

Until recently, empirical studies on the social impacts of cell phones have been fairly meager. Currently, researchers have approached the examination of this phenomenon through observational methods. Findings imply that cell phone usage has become a disturbing tool when operating in public spaces (Ling, 1999b; 2002; Rosen, 2005, Wei \& Leung, 1999). Based on this literature, we propose an empirical model that includes at least four mediating variables to consider in examining the relationship between cell-phone use and social interaction with proximate others. These include: 1) obligation to caller, 2) presumption of privacy, and 3) limited capacity. In the following section, we will discuss each variable in depth. Fig. (1) shows the proposed model with mediating relationships.

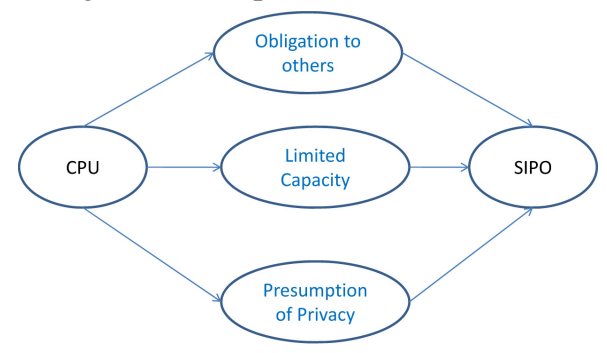

Fig. (1). CPU Model with Mediators.

\section{MEDIATING VARIABLES}

According to Ling (2002), the dynamic of the cell phone in a public setting inevitably brings into question the application of verbal versus non-verbal communication.

In social settings, non-verbal signals are primary indicators of communication (Burgoon \& Hoobler, 2002). We rely on others' signals to interpret their messages in order to manage the interactions that take place in the public sphere. However, according to Ling (2002) the presence of a cell phone automatically restricts users from non-verbal communication. Instead, the use of cell phones in public spaces creates a need for users to establish the distinct nature of their activity. Ling argues that by employing different non-verbal cues, users are able to separate themselves from co-present interactions, limiting their likelihood of non-verbal interaction. We argue that among these non-verbal cues exist two important mediating variables: obligation to others and presumption of privacy.

\section{Obligation to Proximate and Distant Others}

This variable suggests that cell phone users often struggle between proximate others and distant others (people who are on the other side of the cell phone). One of the reasons that cell phone users are reluctant to initiate conversations or awareness of proximate others is because they feel obligated to their phone call. Caller hegemony, a term invented by Hopper (1992), suggests that a defining characteristic of phone conversation is the asymmetrical relationship between the caller and the answerer on a telephone. That is, the caller acts, the answerer must react. Therefore, caller hegemony is maintained by the social norm of giving a calling phone high priority; the norm is to answer an incoming phone (Hopper, 1992; Humphreys, 2003; Bergvik, 2004).

However, cell phone users are also obligated to the person they are with physically. Goffman (1971) suggests that people are subject to expectations both to the person on the phone and the person with them. In some circumstances, managing the expectations for one relationship may be harmful to the other. Mobile technologies, then can pose a serious conflict between an individual's private and public sphere (Cuminskey, 2005). Because of the social obligations to both the person on the phone and the person they are physically with, callers have to constantly negotiate their social rela- 
tions on two fronts, such as passing non-verbal cues to the proximate others, or asking distant others to wait, and when one comes back to the call one would say sorry to the distant others unexceptionally (Humphreys, 2003). However, this is moderated by the interaction status of the proximate others.

People build expectations based on prior experiences and knowledge of similar situation (Bergvik, 2004). For example, we do not expect to interact with strangers unless it is necessary (e.g., emergency). Therefore, it is safe to assume that when one is on the cell phone, he or she does not expect to interact with strangers, for the chance of initiating a conversation with strangers is small to begin with (i.e., even in the absence of a cell phone). However, the social norm of helping others who are in need can break the usual interaction expectation with strangers. But with the presence of cell phone, the same social norm can be diluted and lower the interaction expectation. Although literature shows that we are less likely to interact with unfamiliar social proximate others, we argue that the presence of a cell phone further decreases the possibility of that interaction.

\section{Presumption of Privacy}

The concept of privacy or personal space naturally implies an invisible three-dimensional zone that surrounds an individual (Beaulieu, 2004). Private space enables individuals to regulate their interactions in concordance with public space. Strangers, especially, use several means to communicate distance between them and proximate others (Schelfen $\&$ Aschcraft, 1976). The 'presumption of privacy' variable suggests that people use the cell phone to both signal to proximate others they want to be left alone while at the same time communicating that they are not alone.

Current research on new technologies examines how the uses of these technologies invade and distort the boundaries in public space. Bugeja (2005) argued that new technologies create an alternate reality for its users causing us to dwell in a more virtual habitat than the physical habitat surrounding us. The features of cell phones propose a conflict of space and time, being in two or more places at one time (Bugeja, 2005; Ling, 2002). Therefore, the private features of the cell phone may be viewed as intrusive to the engagement of social interaction in public space (Cooper, 2002).

Little, Briggs, and Coventry (2005) contend that public space in America communicates an established resistance to co-existing proximate others. Scheflen and Aschcraft (1976) suggest that humans exhibit certain territorial behaviors and movements to establish their unit of space and separation from others in shared space. Research on territorialism finds this kind of communication of avoidance and exclusion most common among strangers (Scheflen \& Ashcraft, 1976). Similar to animal communication styles, humans instinctively judge situational factors and choose to express privacy as a tool of protection in social interactions (Beaulieu, 2004; Bugeja, 2005; Little et al., 2005). For instance, research has shown that people have the tendency to manipulate their environment by cupping their chin and turning their gaze in order to communicate this privacy (Chan, 2000; Scheflen \& Aschcraft, 1976). Given this supposition, it is arguable that cell phone users use the device as a means to establish their boundaries in the public sphere (Ling, 2002, Scheflen \& Ashcraft, 1976).
Another aspect of the presumption of privacy involves users' need to express social status. Goffman (1963) suggests that people who are alone in public engage in activities to legitimate their solitary presence. Research shows that the mere presence of cell phone can lead to cell phone use when one is alone in the public area or one is not "really doing anything"' (Humphreys, 2005). Here, cell phone provides legitimacy for being alone in public. In other words, talking on a phone can indicate the existence of other social relations.

Humphreys' (2003) field study showed that by speaking softly, turning their backs to those around them, leaning forward, or speaking with their head downward, cell phone users communicate a requirement of privacy so that other people would not and could not bother them. Here, cell phone becomes a channel for isolation from the immediate environment. Others seemingly recognize the callers' territory and help create the "privacy area" by engaging in selfdistracting activities such as reading a menu or otherwise trying to avoid any tendency to intrude.

As stated before, the use of the cell phone can either be used to invite or shun proximate others. However, we argue that the sheer physical presence of the device automatically invites the presumption of privacy. Therefore, cell phone users are less likely to engage in SIPO because they have created for themselves a private sphere which they control. By clutching to the phone, they make themselves inaccessible by declaring immunity from social interaction.

\section{Limited Capacity}

Research shows that human cognitive capacity is limited. People's capacity and performance on several cognitive dimensions such as memory, attention and reaction time on various tasks are reduced when engaged in dual or multiple activities, or introduced to complex situations involving multiple stimuli (e.g., Broadbent, 1982). For instance, findings indicate that drivers are less likely to comply with red light regulations and increase the accident probabilities when using the phone while driving (Hancock, Lesch, \& Simmons, 2003; Liu \& Lee, 2005). Recent research shows people having greater difficultly maintaining a fixed speed, or keeping their car safe in a single lane when performing tasks that simulated conversing on a cell phone, than if they were driving without the distraction. Contrary to expectation, the speaking and listening were equally distracting (Cell Phone Users Beware, 2005). Overall research shows that driving while on the phone impairs judgment and recognition memory (Liu \& Lee, 2005; Strayer, Drews, and Johnston, 2003). Bugeja (2005) and Urgo (2002) argue that this may be due to the ubiquitous features of technologies that intrude our attentions. While some argue that various things could attribute to distraction while driving, studies on the distraction effect indicate that cell phone use is distinct because it requires a high level of cognition and physical demand (Liu and Lee, 2005).

Similar effects of cell phone use on other non-driving tasks are expected as well, including the variety of social interactions people take part in, the dual tasks of interacting and participating in local social interaction and managing a concurrent cell phone conversation may represent a kind of cognitive overload for the phone user. Meyerowitz (1985) 
suggested that cell phone users tend to be less aware of their surroundings. This may lead to reduced attention to and awareness of certain features in the local social interaction (Bergvik, 2004). Oulasvirta (2005) calls this phenomenon "fragmentation of attention in mobile interaction" and demonstrates that mobile users engage in strategic withdrawal of cognitive resources from competing tasks that they deem less important. Hence the slowing down of the pace in walking by a pedestrian sending a text message on the cell phone or the reduction in the exuberance of one's greeting of an acquaintance on the street while one is chatting on the phone.

We argue that the use of cell phones will cause distraction or a lack of involvement and awareness of our environment due to limited capacity. This variable captures the idea that while on the cell phone we are cognitively less accessible to our immediate external surroundings.

While these mediating variables are important to consider in examining the relationship between CPU and SIPO, the nature and magnitude of this relationship are dictated by at least two moderating variables.

\section{MODERATING VARIABLES}

The first moderator is the Interaction Status with Proximate Others. Wei and Leung (1999) reported that people find cell phone conversations disturbing when they are engaged in a joint activity with the cell phone users. Therefore, the persons users were with and the tasks users were engaged in before talking on the cell phone can have different degrees of influences on their perception of obligation and interaction expectation with proximate others. For example, if one is chatting face-to-face with a proximate friend, one is less likely to make a call to the distant person as one feels obligated to the person one is with. If the distant person calls in, one might feel more obligated to take care of the proximate friend while talking on the phone than when one is alone. One would be expected to show more non-verbal cues to the proximate other, such as nodding, eye-contact with apology, and signaling with the hand that this call will take " "just one minute" (Humphreys, 2003). Thus, one's obligation to proximate others as well as indications of privacy are likely to vary as a function of the status of one's interaction with the proximate other prior to cell phone conversation. Fig. (2) shows the full proposed model.

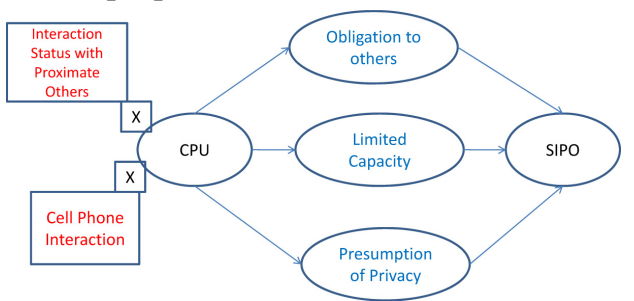

Fig. (2). CPU Model with Moderators and Mediators.

The second moderator significant to this model is Cell Phone Use Initiation. Depending upon who initiates the call, cell phone users' obligation to the distant others and their interaction expectation with proximate others would vary. Caller hegemony is more likely to happen when the distant others initiate the call than when the cell phone users themselves do. In addition to conveying a different sense of obligation as well as presumption of privacy, this might be ac- companied by a higher-than-usual disturbance in the allocation of cognitive resources because the occurrence of the call does not allow the user to preprogram himself/herself for distribution of resources between the proximate and distant others.

These are but two moderating variables that are likely to play a significant role in our understanding of how the presence of the cell phone in public space affects social interaction with those around us. There might be many more moderators as well as mediators involved in this relationship. Identifying them and specifying their role in the relationship would vastly enrich the proposed tentative model. However, theory-building should also go hand in hand with empirical testing. We offer one small test here, wherein we examine how cell phone usage affects social interaction in the context of social participation. Specifically, we study how the presence of the cell phone affected helping behavior.

\section{EXPERIMENTAL APPLICATION: TO HELP OR NOT TO HELP?}

To empirically test the relationship between CPU and SIPO, we chose to examine how CPU may affect a form of SIPO in social participation. We argue that the limitedcapacity variable in our model will be most prominent in a helping context. Researchers selected Helping Behavior as it appears to be one of the strongest values of social interaction between strangers in our society. The following provides a thorough overview of our experiment; however we will first briefly discuss our conceptualization of Helping Behavior.

\section{Helping Behavior}

Social participation has varied forms, and Helping Behavior is a major element (Statistics Canada, 2003). There are two psychological notions of Helping Behavior: altruism and egoism (Guenther, et al., 1996). Altruism help is the behavior that helps a person in need and is driven purely by the desire to help the other person, while egoism help is the behavior that people help each other based on some sort of personal gain. In this study, Helping Behavior refers to the unpaid help that one gives to other people (not including help where one makes a living and those one gives as a volunteer for an organization). Specifically, we looked at the " "anonymous helping of strangers in one-time interactions (McGuire, 2003, p.365).",

Researchers have long been trying to explain why people do not help each other (Darley \& Latané, 1968). One of the important reasons is that helping behavior decreases as the number of bystanders increases - the bystander effect (Cialdini, 1993; Darley \& Latané, 1968; Latané \& Darley, 1969). One explanation for the bystander effect is the diffusion of responsibility. Bystanders assume that someone else will take the responsibility to help the person/persons in need. Extending this to the cell phone context, users are likely to feel a diminished sense of obligation to a proximate person because, psychologically, the fact that they are interacting with another person, albeit over the phone, makes them feel like a bystander with a license to be apathetic to their immediate surroundings. Since cell phone usage in public spaces poses a conflict between space and time, it might be possible that cell phone users have a false sense of others, unconsciously presuming that the person that they are on the phone 
with is present. Also based on the idea of limited capacity and the consequent fragmentation of attention, they just may not be aware of others while on the phone.

Therefore, because cell phone use can distract people's attention to others' needs, as well as give people the psychological feeling of diminished obligation toward others, we propose the following hypothesis:

Hypothesis I: Cell Phone Accessibility (CPA) is negatively related to Helping Behavior toward strangers compared to No Cell Phone Accessibility (NCPA).

\section{Social Cues (Smiling)}

Social cues are a significant form of non-verbal communication that can either signify openness or connote presumption of privacy. In our study, we used Smiling as an operationalization of the social cue used to signify a diminished presumption of privacy on the part of the cell-phone user. Not only do our faces signal emotions, but they are also most significant in our social interaction (Argyle, 1988). We wanted to see how Smiling is affected by cell phone accessibility and how it affects further Helping Behavior because the role played by this variable would be an indirect verification of the mediation of privacy presumption proposed in our model.

Based on this literature, we have developed the following hypotheses:

Hypothesis IIa: CPA will result in lesser number of friendly gestures such as Smiling than NCPA.

Hypothesis IIb: People who show more friendly gestures such as Smiling will help more than those who do not smile.

Hypothesis IIc: Presumption of privacy will mediate relationship between Cell Phone Accessibility and Helping Behavior.

Lastly, we assume that if those who use their cell phones should happen to help, there will be a difference in the time it takes for cell phone users to help due to the distraction posed by the cellular phone (i.e., the limited-capacity mediation explanation). Therefore, we posit:

Hypothesis III: Time taken to initiate Helping Behavior will be longer under conditions of CPA compared to NCPA.

\section{MATERIALS AND METHODOLOGY}

Most research on cell phone use takes place in naturalistic settings, where users' behaviors are observed. In his observational studies of cell phone usage in European cities, Ling (1999b) not only recorded cell phone usage, but noted users' body language, including gaze, bodily position, and facial expression. For our research question, we chose to design an experiment where we could slightly manipulate the environment so that we could observe participant behavior under a controlled condition. We hosted our experiment in a room that included a two-way mirror. This way, observers could see the participants, but participants could not see the observer. Chairs in the experiment room were set up to face the mirror, leaving no option for sitting elsewhere. This allowed researchers to accurately view the participant.

Our experiment consisted of four major roles: experimenter, confederate, observer and gatekeeper. Below is the description of each role.

\section{Experimenter}

The experimenter of the study sessions greeted participants, explained the nature of the study, and administered the actual tasks and questionnaires employed in this study. When needed, the experimenter also functioned as the gatekeeper.

\section{Confederate}

The confederate in this study was a student volunteer. The role of the confederate was designed to appear as though the confederate had lost something important. The confederate was trained over the course of two weeks to search key areas of the experiment room, looking frantic, concerned and anxious. The trained confederate was sent into the room by the observer (described below) usually about a minute after the participant entered the room. After 2 minutes of searching the confederate left the room.

\section{Observer}

Perhaps the most challenging task was that of the observer, who was hidden in the observational room. The role of the observer was to code for Cell Phone Accessibility $(0=$ No Cell Phone Accessibility, 1= Cell Phone Accessibility), Smiling to the confederate $(0=$ No smiling, $1=$ Smiling $)$, Helping Behavior $(0=$ No Help Offered, $1=$ Offered Help) and the time taken by the participant to offer help to the confederate. When the participant was alone in the room, the observer immediately began timing. As soon as the participant was observed speaking to an actual person on their cell phone, the observer sent the confederate into the room. Otherwise, the observer waited a minute before sending the confederate. After sending in the confederate, the observer restarted the timing. While the confederate was in the room, the observer coded for participant's smiling behavior. The observer also coded for whether or not the participant offered help and the length of time it took participants to offer help.

\section{Gatekeeper}

The role of the gatekeeper was essentially to keep participants who may have arrived early or late shielded from the experiment. This role was designed because early or late students could easily enter experimental room and would be exposed to the confederate early than desired, jeopardizing the manipulation of the study. As a mask to the study, the gatekeeper usually prepared participants for the study by administering informed consent forms.

\section{Apparatus}

For this study, we employed an entertainment trivia task (see Appendix 1) and two questionnaires (see Appendix 2, 3 ). Because we sought to control for cell phone use habit, we developed our own questionnaire including two questions about cell phone ownership and frequency of cell phone use. Borrowing from Ling's research on the intrusive nature of cell phones in public spheres, the scale also consisted of two subscales measuring places of phone accessibility and places of phone use.

We also considered that personality might play a role in an individual's likelihood to help. In order to control for personality, we used Big Five Personality Inventory Scale (John 
\& Srivastava, 1999). The BFI is a self-report questionnaire featuring a 7-point Likert scale that ranges from 1 (strongly disagree) to 7 (strongly agree).

For the entertainment task, we developed five questions about the latest news on various popular television shows, including American Idol, Sex and the City and MTVs Punk'd. The purpose of these questions was to elicit social conversation as entertainment news is often associated with gossip.

\section{Sample Participants}

Subjects were recruited from various communications courses where they were invited to participate in a research study about 'Media Viewing Behavior'. Our sample consisted of 28 students. Seventy-eight percent of our sample majored in communications, while the remaining $22 \%$ majored in Communication Arts and Sciences, English or Education. Seventy-five percent of our sample was female, while the remaining $25 \%$ was male. Participants received a compensation of one extra credit point in their class for participating in our study.

Participants' decision to use the cell phone served as the primary determinant of the condition in which the participant was placed. If a participant did not use the cell phone, then the observer coded the participant as belonging to the NCPA condition. If the participant used the cell phone, then he/she was automatically placed in the CPA condition.

\section{Procedure}

Students were asked to sign up for individual 30-minute sessions to participate in a study about 'Media Usage Behavior'. Upon arrival at the lab, each study participant was handed an informed consent form and instructed to read and sign both copies, giving one copy to the experimenter. After signing the informed consent form, the participant was informed that the session will include two short questionnaires and an entertainment task. The experimenter of the session explained to the participants that the purpose of the entertainment task was to function as a "“cognitive warm-up"”, to prepare them for the actual questionnaires. Participants were encouraged and instructed to respond to the five entertainment trivia questions to the best of their ability. They were also strongly encouraged to call a friend to verify their answers. After giving instructions, the experimenter informed the participant that she would leave the room to prepare the questionnaires for the rest of the study. Participants were told that the experimenter would return in about five minutes.

When the experimenter left the room, the observer watched the participant to code for cell phone use or no cell phone use. After 1-2 minutes of observation, the confederate entered the room. For 1-2 minutes, the confederate searched throughout the room for a missing object. If the participant offered help before the two minute mark, then the confederate left the room. The confederate was trained to explain that she was looking for her keys. The participant was watched to see if they appeared to help the participant by looking around for the set of keys, or by offering suggestions to help the confederate. If the participant did not offer any help before the two minute mark, after two minutes the confederate left the room without saying a word to the participant.

After the manipulation of the confederate, the experimenter waited two minutes before re-entering the room. After re-entering the room, the experimenter administered the personality questionnaire and the cell phone use habit questionnaire. The experimenter left the room and informed the participant that she would return momentarily to retrieve the questionnaire. After sufficient time, the experimenter reentered the room to collect all the questionnaires. Participants were informed that they would receive their debriefing via e-mail so as to protect the confidentiality of the study from potential participants in shared circles. After two weeks of the completion of the study, participants were emailed and thanked for their participation in the study.

\section{RESULTS}

Among all the participants $(\mathrm{n}=28), 11(39.29 \%)$ were in the CPA group while $17(60.71 \%)$ were in the NCPA group. Total 8 people $(28.57 \%)$ helped while 20 people $(71.43 \%)$ did not. All the Helping Behavior occurred in the NCPA group; noone helped in the CPA group. Among our sample of 28 participants, only $10(35.71 \%)$ smiled, which was unevenly distributed between NCPA group $(n=9)$ and CPA group $(n=1)$. Among all the Smilers $(n=10), 6$ offered help and 4 did not offer help. Among all the Non-smilers $(n=18)$, only 2 helped.

The first hypothesis test examined the relationship between Cell Phone Accessibility and Helping Behavior. It predicted that people in the CPA group are less likely than people in the NCPA group to help strangers. Logistic stepwise regression confirmed Hypothesis I,

$$
\mathrm{R}^{2}=.30, \mathrm{~L}-\mathrm{R} \chi^{2}(1, \mathrm{~N}=28)=9.99, p<.01 \text {. (Fig. 3). }
$$

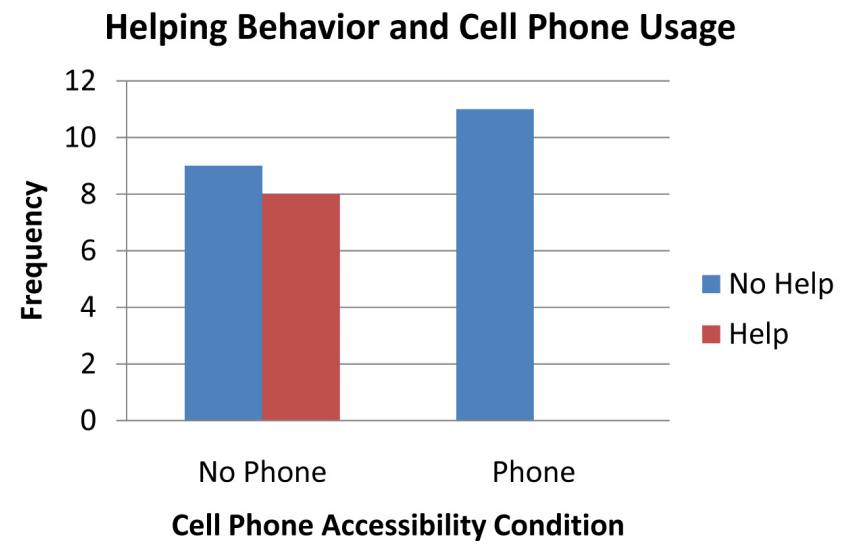

Fig. (3). Those who used cell phones were less like to help compared to those did not use a cell phone.

The second hypothesis, which was proposed in order to test whether social cues is a mediator, consists of three subhypotheses. Hypothesis IIa predicted that people in the CPA group will show less social cues such as Smiling behavior than people in the NCPA group. Logistic stepwise regression confirmed Hypothesis IIa, $\mathrm{R}^{2}=.17, \mathrm{~L}-\mathrm{R} \chi^{2}(1, \mathrm{~N}=28)=6.29$, $\mathrm{P}<.05$. (Fig. 4). 
Smiling Behavior and Cell Phone Usage

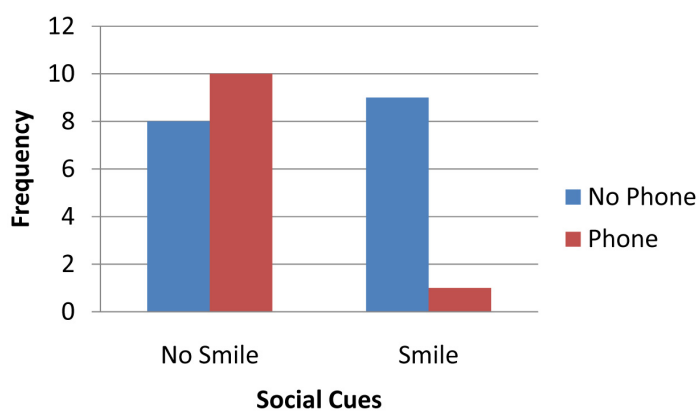

Fig. (4). Those who used cell phones were less likely to smile at the confederate than those who were not using cell phones.

Hypothesis IIb predicted that people who show more social cues such as Smiling will help more than those who do not smile. Logistic stepwise regression confirmed Hypothesis IIb, $\mathrm{R}^{2}=.22, \mathrm{~L} \mathrm{R} \chi^{2}(1, \mathrm{~N}=28)=7.48, \mathrm{P}<.01$. Hypothesis IIc predicted that social cues such as Smiling as an operationalization of presumption of privacy will mediate the relationship between Cell Phone Accessibility and Helping Behavior. Logistic stepwise regression confirmed Hypothesis IIc, $\mathrm{R}^{2}=.39, \mathrm{~L}-\mathrm{R} \chi^{2}(1, \mathrm{~N}=28)=5.56, \mathrm{p}<.05$.

Hypothesis III proposed that participants in the CPA group will take longer than their counterparts in the NCPA group to help strangers. However, this hypothesis could not be tested due to the fact that nobody in the CPA group helped. Moreover, there were no significant findings yielded when analyzing the influence of personality on Helping Behavior. Data from cell phone habit use also did not yield any significant relationships.

In sum, results of the experiment supported the basic hypothesis pertaining to the negative relationship between cell phone usage and an individual's social interaction with proximate others predicted by the model. Cell phones indeed seem to significantly curtail social interaction, operationalized by way of an altruistic behavior. Furthermore, the nonverbal communication of a presumption of privacy emerged as a significant mediator in the relationship.

\section{CONCLUSIONS}

At the beginning of this project, we set out to develop a theoretical model for which the social effects of cell phone usage in public spaces can be empirically tested. In our model, we argued that before CPU may affect SIPO, users must either initiate a phone call or be receivers of a phone call. Prior interaction status with proximate others is also significant to users' social interaction with proximate others. When they are in the midst of proximate others, cell phone users experience an obligation toward both the distant and the proximate others, show a desire for privacy, and are cognitively distracted forcing them to distribute their attention between the caller and the proximate other. All of this serves to alter their interaction with proximate others. Although research already indicates that social interaction with strangers is minimal (Scheflen \& Aschcraft, 1967), this model attempts to argue that the presence of a cell phone reduces interaction even further. So much so that it could affect our social responsibility to proximate others, be they familiar or known others.
In an attempt to examine this relationship we investigated the relationship between Cell Phone Usage and Helping Behavior. According to our findings, those who used their cell phones were less likely than those who did not use their cell phones to offer help to the confederate. The results of our study indicate that the accessibility and usage of a cellular phone may inhibit users from offering help to strangers who are in need. Such neglect could prove to be damaging to our society. Consistent with other research findings such as Bergvik (2004), the accessibility and usage of the cell phone created a form of exclusion and social isolation that hindered users from recognizing others' needs. The fact that cell phone use inhibited altruistic behavior (rather than some other type of social interaction) is theoretically important because it implies a reduced obligation to proximate others. If the same level of inhibition is observed in other, less obligatory, social interactions, then we may be able to implicate other mediators of the relationship.

Our findings also indicate that the accessibility and usage of a cell phone also has the potential to inhibit non-verbal social cues such as Smiling that are useful in social interaction with proximate others. Those who used their cell phones were less likely than those who did not use their cell phones to smile at the confederate. Accessibility of the cell phone may cause cell phone users to exhibit non-friendly behaviors towards strangers without being aware of their rudeness. These findings lend support for the presumption of privacy as a significant mediating variable in the CPU-on-SIPO model.

However, the significance of the third mediator, limited capacity, could not be tested due to the aforementioned floor effect (i.e. none of the CPA participants helped the confederate), thus rendering moot the measurement of the time to offer help (our operationalization of limited capacity). Future research would do well to assess the cognitive burden imposed by CPU with the help of distracters. The degree to which CPU immerses users as they insulate themselves from their surroundings may be indicated by the latency of their response to distracters, much like in secondary task measures of attention to media (e.g., Basil, 1998).

Future research may also be directed towards identifying other mediators which may serve to enhance the universe of explanations for the variance in SIPO that is accounted for by CPU.

\section{Limitations}

It is possible that CPA participants were less likely to help because they were concentrating on performing the task, but this is unlikely to be an alternative explanation because both the CPA and NCPA conditions were exposed to the task.

Our CPU-on-SIPO model faces many challenges in its attempt to empirically analyze cell phone usage. Arguably, it is challenging to manipulate each of the variables present in the model. Our attempt to control the environment in this study also proves to be a limitation. Cell phone use behavior and social interaction is an everyday leisurely activity that is hard to manipulate. Future research should consider observing cell phone use behavior in a more realistic setting. For example, a confederate may be used in a more public and natural environment or situation. Since the direness of the 
helping situation also proves to be a limitation, future research ought to consider creating a more urgent situation to elicit Helping Behavior. For example, the confederate could be carrying something heavy and need assistance with entering a building. In this case, we could observe the time take by cell phone users offer necessary help. Employing such methods would allow for a natural realistic setting while still maintaining the controlled nature of classic experimentation.

\section{Implications}

The findings of this study have many implications not just for cell phones, but also for other interactive mobile technologies including ipods, PDAs, and GPS systems. Concurring with research on the intrusive nature of cell phones, we posit that the interactive and mobile nature of these technologies allow for distractions in public spheres (e.g., Oulasvirta, 2005). It appears that the privatization of these technologies do not fare well in public spaces as it diffuses our responsibility to help those outside of our social group. Cell phones, along with other interactive and mobile communication technologies, function as masks that hinder active users from recognizing the needs of others.

The implications of this study are not only empirical, but serve to demonstrate the dangers that mobile communication technologies may pose if not used properly. Discretion of cell phone use is even evident in current state laws that prohibit drivers from talking on the phone while driving. This alone testifies to the potential risk of danger that interactive mobile technologies pose for its users. A possible solution is to make users more aware of the effect of these mobile technologies on their attention, not only to strangers but even their surroundings. As proper etiquette exists for internet behavior, perhaps we ought to develop a social code of behavior for proper cell phone usage.

\section{ACKNOWLEDGEMENTS}

The authors would like to thank Stevie Woodring for her participation as the confederate in this experimental study. The authors would also like to thank the reviewers for their insight and suggestions on working drafts of this article.

\section{SUPPORTIVE/SUPPLEMENTARY MATERIAL}

Appendix 1

Entertainment task used as the cognitive warm up.

Appendix 2

Cell phone use habits questionnaire used to assess participants' dependence and usage of the mobile technology.

\section{REFERENCES}

Argyle, M. (1988). Bodily Communication ( $2^{\text {nd }}$ ed). New York, NY: Methuen \& Co. Ltd.

Beaulieu, C. (2004). Intercultural study of personal space: A case study. Journal of Applied Social Psychology 34, 794-805.

Bergvik, S. (2004). Disturbing cell phone behavior - A psychological perspective. Implications for mobile technology in tourism. Retrieved March 12, 2005 from World Wide Web: http://www.telenor.com/rd/pub/rep04/R_29_2004.pdf

Broadbent, D.E. (1982). Task combination and selective intake of information. Acta Psychologica 50(3), 253-290.

Bugeja, M. (2005). Interpersonal divide. New York, NY: Oxford University Press.
Burgoon, J.K., Hoobler, G. (2002). Nonverbal signals. In M.L. Knapp, J. Daly (Eds.), Handbook of interpersonal communication (pp. 240299). Thousand Oaks, CA: Sage.

(2005, August 26). Cell phone users beware: Talking and listening impairs your ability to drive safely. Retrieved October 29, 2005, from the World Wide Web: http://www.sciencedaily.com/releases/2005/08/050826073950.htm

Cialdini, R.B. (1993). Influence: The psychology of persuasion. New York, NY: Morrow.

Chan, Y. (2000). Privacy in the family: Its hierarchical and asymmetrical nature. Journal of Comparative Family Studies 31(1), 1-23.

Cooper, G. (2002). The mutable mobile: Social theory in the wireless world. In B. Brown, N. Green, and R. Harper (Eds.), Wireless world: Social and interactional aspects of the mobile Age (pp. 19-31). New York, NY: Springer.

Cumiskey, K. (2005) Surprisingly, nobody tried to caution her: Intentionality and the role of social responsibility in the public use of mobile phones. In R. Ling, \& P. Pedersen (Eds.), Mobile communications: re-negotiation of the social sphere (pp. 225-236). London: Springer-Verlag.

Darley, J., \& Latané, B. (1968). Bystander intervention in emergencies: Diffusion of responsibility. Journal of Personality \& Social Psychology 8(4), 379

Goffman, E. (1963). Behavior in public spaces. New York, NY: Free Press

Goffman, E. (1971). Relations in public: Microstudies of the public order. New York, NY: Harper.

Guenther, K., Lesniak, J., Magnuson, A., \& Underwood, K. (1996). Altruism on the far side. Psy 324: Advanced Social Psychology, Miami University. Retrieved May 06, 2005 from the World Wide Web: http://www.units.muohio.edu/psybersite/Humor/p324hum3.shtml

Hancock, P.A., Lesch, M., \& Simmons, L. (2003). The distraction effects of phone use during a crucial driving maneuver. Accident Analysis and Prevention 35, 501-514.

Hopper, R. (1992). Telephone conversation. Bloomington, In: Indian University Press.

Humphreys, L. (2003). Can you hear me now? A field study of mobile phone usage in public space. Unpublished master's thesis, University of Pennsylvania, Pennsylvania.

Humphreys, L. (2005). Cell phones in public: Social interaction in a wireless era. New Media \& Society 7(6), 813-836.

John, O.P., \& Srivastava, S. (1999). The big five trait taxonomy: History, measurement, and theoretical perspectives. In L.A. Pervin \& O.P. John (Eds.), Handbook of personality theory and research (pp. 102-138). New York, NY: Guilford Press.

Lang, A. \& Basil, M.D. (1998). Attention, resource allocation, and secondary task reaction times in communication research: What do secondary reaction task reaction times measure, anyway? In M.E. Roloff (Ed.), Communication Yearbook, 21 (pp. 443-473). Newbury Park, CA: Sage Publications.

Latané, B., \& Darley, J. (1969). Bystander "Apathy" American Scientist 57, 244-268.

Ling, R. (1999). "I am happiest by having the best": The adoption and rejection of mobile telephony. R\&D Report, (15). Kjeller, Norway, Telenor.

Ling, R. (1999). Restaurants, mobile phones and bad manners: New technology and the shifting of social boundaries. Human Factors in Telecommunications, 17th International Symposium. Coppenhagen, Denmark.

Ling, R. (2002). The social juxtaposition of mobile telephone conversations and public spaces. Paper presented at the conference on Social Consequences of Mobile Telephones. Chunchon, Korea.

Liu, B. \& Lee, Y. (2005). Effects of car-phone use and affective disposition during critical driving maneuvers. Transportation Research Part F $8,369-382$.

Little, L., Briggs, P., \& Coventry, L. (2005). Public space systems: Designing for privacy. Human Computer Studies 63, 254-268.

McGuire, A.M. (2003). "It was nothing" - Extending evolutionary models of altruism by two social cognitive biases in judgments of the costs and benefits of helping. Social Cognition 21(5), 363-394.

Meyrowitz, J. (1985). No sense of place: The impact of electronic media on social behavior. New York, NY: Oxford University Press.

Oulasvirta, A. (2005). The fragmentation of attention in mobile interaction, and what to do with it. Interactions: New Visions of HumanComputer Interaction 12(6), 16-18. 
Plant, S. (2001). On the mobile: the effects of mobile telephones on social and individual life. Retrieved May 06, 2005 from the World Wide Web: http://motorla.com/mot/documents/o.1028.333.00.pdf

Priest, R. (1998). Would you stop to help him? A lecture in helping behavior. Social_Psychology.net. University of Southern Indiana. Retrieved May 06, 2005 from the World Wide Web: http://www.usi. edu/libarts/socio/socpsy/helping.htm

Rosen, C. (2005, March 20). Bad connections: Cell phones, iPods and TiVo in the age of egocasting. The New York Times Magazine.

Scheflen, A.E. \& Ashcraft, N. (1976). Human territories: How we behave in space-time. Englewood Cliffs, NJ: Prentice-Hall.
Statistics Canada (2003). General Social Survey - Social Engagement (GSS). Retrieved May 06, 2005 from the World Wide Web: http://www.statcan.ca/english/sdds/instrument/5024_Q1_V1_E.pdf

Strayers, D.L., Drews, F.A., \& Johnston, W.A. (2003). Cell phone induced failures of visual attention during simulated driving. Journal of Experimental Psychology Applied 9, 23-32.

Urgo, J. (2000). In the age of distraction. Jackson, MI: University Press of Mississippi.

Wei, R., \& Leung, L. (1999). Blurring public and private behaviours in public space; Policy changes in the use of the cell phone. Telematics and Informatics 16, 11-26.

(C) Banjo et al.; Licensee Bentham Open.

This is an open access article licensed under the terms of the Creative Commons Attribution Non-Commercial License (http://creativecommons.org/licenses/by-nc/3.0/) which permits unrestricted, non-commercial use, distribution and reproduction in any medium, provided the work is properly cited. 